\title{
Comunicação
}

[Communication]

\section{Investigação de anticorpos contra Sarcocystis neurona e Sarcocystis cruzi em equinos}

\author{
[Investigation of antibodies against Sarcocystis neurona and Sarcocystis cruzi in equines] \\ A.M. Antonello ${ }^{1}$, F.L. Pivoto $^{1}$, G. Camillo $^{1}$, P. Braunig ${ }^{1}$, L.A. Sangioni ${ }^{1}$, \\ E. Pompermayer ${ }^{2}$, M.C. Venturini ${ }^{3}$, F.S.F. Vogel ${ }^{1}$ \\ ${ }^{1}$ Centro de Ciências Rurais - CCR-UFSM - Santa Maria, RS \\ ${ }^{2}$ Qatar Racing \& Equestrian Club, Doha, Qatar \\ ${ }^{3}$ Faculdad de Ciencias Veterinarias - Universidad Nacional de La Plata - La Plata, Argentina
}

Equinos podem ser hospedeiros intermediários de varias espécies do gênero Sarcocystis, como $S$. fayeri, $S$. equicanis e $S$. bertrami, que completam seu ciclo em cães (Tenter, 1995), além de $S$. neurona, cujo hospedeiro definitivo é o gambá (Didelphis sp.) (Dubey et al., 2001a). S. neurona é descrito como principal agente causador da mieloencefalite equina por protozoário (MEP), uma enfermidade infecciosa de caráter neurológico e muitas vezes fatal (MacKay et al., 2000). A principal ferramenta para o diagnóstico ante mortem da MEP é a sorologia (Johnson et al., 2010), que é um método de detecção indireto da exposição ao parasita, o que não significa que esteja ocorrendo infecção ativa pelo protozoário no animal soropositivo. No Brasil, os registros da exposição de equinos ao agente são escassos. Hoane et al. (2006) encontraram $69,6 \%$ de animais soropositivos para $S$. neurona em diferentes regiões do Brasil, o que demonstra a grande exposição dos animais ao protozoário.

S. cruzi, por sua vez, tem seu ciclo relacionado a cães (hospedeiro definitivo) e ruminantes (hospedeiros intermediários). É bastante relatado em bovinos, podendo causar lesões musculares e baixo ganho de peso. Os índices de reatividade sorológica para S. cruzi podem beirar os $100 \%$ em um rebanho bovino (Moré et al., 2011).

O ciclo biológico de $S$. neurona e $S$. cruzi é similar, embora envolva diferentes espécies de hospedeiros definitivos, gambás do gênero Didelphis spp. e cães (Canis lupus familiaris), respectivamente (Dubey et al., 2001a; Xiang et al., 2011). Os hospedeiros intermediários se infectam pela ingestão de esporocistos presentes no ambiente. Após estabelecida a infecção, $S$. neurona tende a permanecer no tecido nervoso (Dubey et al., 2001b), enquanto $S$. cruzi tende a formar sarcocistos no tecido muscular (Moré et al., 2011) dos hospedeiros intermediários. A infecção do hospedeiro definitivo ocorre pela ingestão de tecidos infectados, com consequente liberação de esporocistos nas fezes, contaminando o ambiente (Dubey et al., 2001b; Xiang et al., 2011).

A sorologia é a principal ferramenta no diagnóstico ante mortem da MEP, uma vez que a detecção direta do parasita é muito difícil antes da necropsia. Mediante o status sorológico, combinado à avaliação clínica, são tomadas as medidas terapêuticas. No entanto, a presença de anticorpos contra Sarcocystis spp. indica exposição ao agente, mas não necessariamente persistência da infecção. Há ainda o risco de reação cruzada entre as duas espécies de Sarcocystis, devido à proximidade filogenética entre protozoários do mesmo gênero, no momento em que se recorre a testes sorológicos. Outros autores demonstram a ocorrência de reatividade sorológica entre espécies de Sarcocystis, a que deve ser dada importância no momento do diagnóstico (Saville et al. 2004). Com base no exposto, este estudo foi realizado a fim de fazer uma triagem sorológica em equinos quanto à presença de anticorpos contra antígenos de $S$. neurona e $S$. cruzi.

Recebido em 13 de fevereiro de 2014

Aceito em 14 de março de 2015

E-mail: ana_antonello@hotmail.com 
Foram testadas amostras de soro de 189 éguas Puro Sangue Inglês (PSI) de dois haras, localizados no sudoeste do Rio Grande do Sul, Brasil. Na região, há registros da presença de gambás (Didelphis sp.) e de cães nas propriedades. Os animais eram monitorados rotineiramente por médico veterinário e todas as coletas foram realizadas no momento do parto. $\mathrm{O}$ sangue total foi centrifugado a $250 \mathrm{~g}$ por 10 minutos para a obtenção do soro sanguíneo, que foi estocado a $-20^{\circ} \mathrm{C}$ até o momento do teste. As propriedades e o número de animais testados em que foi realizado o estudo foram selecionados pela facilidade de acesso e disponibilidade dos proprietários.

A pesquisa de imunoglobulinas $\mathrm{G}$ (IgG) anti-S. neurona foi realizada pela técnica de imunofluorescência indireta (IFI). Foram usados como antígeno merozoítos de $S$. neurona da cepa SN-37R cultivados em células da linhagem CV-1.

Os testes para $S$. cruzi foram realizados no laboratório da Universidade Nacional de La Plata, Argentina. Para a preparação das lâminas, foram utilizados bradizoítos coletados de coração bovino infectado, conforme recomendações de Moré et al. (2008).

A diluição do soro sanguíneo em PBS utilizada para a triagem pela IFI, tanto para $S$. neurona como para S. cruzi, foi de 1:50 (Moré et al., 2008). Anticorpo anti-IgG equina conjugado a fluoresceína (FITC) (Affinity Purified Antibody Fluorescein, Clopper Road 910, Gaithersburg, MD 20878 USA, www.kpl.com) foi usado como anticorpo secundário na reação. Amostras de soro sabidamente positivas ou negativas quanto à presença de anticorpos anti-S. neurona (nas lâminas de $S$. neurona) e anti-S. cruzi (nas lâminas de $S$. cruzi), testadas previamente, foram utilizadas como controle positivo e negativo, respectivamente. Foram consideradas positivas as amostras em que houvesse fluorescência em toda a superfície dos bradizoítos/merozoítos de Sarcocystis spp., e negativas as amostras em que a fluorescência era apical ou ausente.

Os resultados da prevalência sorológica de $S$. neurona e $S$. cruzi foram comparados pelo teste de $\chi^{2}$, utilizando-se o software GraphPad Prism $5^{\circledR}$. Esta pesquisa foi aprovada pelo Comitê de Ética e Experimentação Animal da Universidade Federal de Santa Maria, cujo processo está registrado sob número 81/2009.

Os resultados da comparação sorológica de equinos frente a antígenos de $S$. neurona e $S$. cruzi estão expostos na Tab. 1. A frequência de detecção de anticorpos para $S$. neurona e $S$. cruzi foi de 33,86\% (64/189) e 80,42\% (152/189), respectivamente, com diferença significativa entre as duas espécies $\left(\chi^{2}=4,587,1 ; \mathrm{IC}=95 \%\right.$; $\mathrm{p}=0,0322$ ) (Tab. 1). Dos 189 animais testados, $159(84,13 \%)$ reagiram a pelo menos um dos protozoários. Destes, 102 apresentavam anticorpos somente contra um dos agentes - 95 contra $S$. cruzi e sete contra $S$. neurona.

Aproximadamente um terço das éguas soropositivas apresentava anticorpos contra antígenos das duas espécies de protozoário (57/159) (Tab.1), o que sugere a exposição a ambas as espécies de Sarcocystis spp. pesquisadas. Não houve detecção de anticorpos contra Sarcocystis spp. em $30(15,87 \%)$ das éguas testadas. É importante ressaltar que esses mesmos animais, quando testados para Neospora caninum pela mesma técnica, apresentaram 64,5\% de animais sororreativos (Antonello et al., 2012). As éguas testadas são criadas em haras do estado do Rio Grande do Sul, Brasil, demonstrando-se a circulação de Sarcocystis spp. nessa região.

Tabela 1. Imunoglobulinas (IgG) anti-S. neurona e anti-S. cruzi em amostras séricas de éguas por imunofluorescência indireta (IFI)

\begin{tabular}{cccc}
\hline Sarcocystis neurona & \multicolumn{2}{c}{ Sarcocystis cruzi } & \multirow{2}{*}{ Total (\%) } \\
\cline { 2 - 3 } & Positivos & Negativos & \\
\hline Positivos & 57 & 7 & $64(33,86)^{\mathrm{a}}$ \\
Negativos & 95 & 30 & 125 \\
\hline Total $(\%)$ & $152(80,42)^{\mathrm{b}}$ & 37 & 189 \\
\hline
\end{tabular}

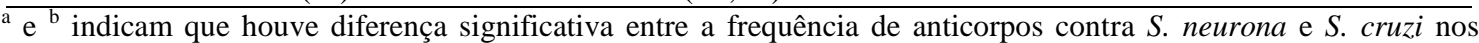
animais $\left(\chi^{2}=4,587 ; \mathrm{IC}=95 \% ; \mathrm{P}=0,0322\right)$. 
A sorologia é a principal ferramenta no diagnóstico ante mortem da MEP. Com base nesse resultado, são tomadas as decisões terapêuticas e/ou preventivas, por isso é importante ter em mente que um resultado positivo não indica necessariamente infecção ativa por $S$. neurona, e, consequentemente, o animal tem menos chance de manifestar MEP de forma clínica. Protozoários de diferentes espécies dentro do gênero Sarcocystis podem expressar as mesmas proteínas em sua superfície (Saville et al., 2004), o que pode levar à ocorrência de reação cruzada. O risco de reatividade cruzada foi minimizado neste trabalho ao se considerarem negativas as amostras em que a fluorescência era apenas apical. De fato, 95 dos animais reagiram somente contra antígenos de $S$. cruzi e apenas sete contra $S$. neurona (Tab. 1), sendo maior a soroprevalência para $S$. cruzi. Em um estudo retrospectivo que utilizou a técnica de imuno-histoquímica em tecidos de equinos diagnosticados com MEP, Hamir et al. (1993) observaram a presença de lesões e esquizontes no sistema nervoso dos animais, as quais reagiam com anticorpos contra $S$. neurona e $S$. cruzi. Curiosamente, no mesmo estudo, os autores também encontraram uma proporção maior de animais reagindo a $S$. cruzi $(67 \%)$ que a $S$. neurona (51\%) na imuno-histoquimica. Esses dados sugeririam que os animais estariam mais expostos a $S$. cruzi, que não é relacionado à MEP.

A presença de $S$. cruzi é mais comum no tecido muscular que no tecido nervoso de bovinos, acarretando perdas de produtividade no rebanho. O sistema de criação de bovinos disseminado no Sul do Brasil, aliado ao estreito contato com cães (hospedeiros definitivos), que permite a eficiente passagem de parasitas de canídeos para bovinos e vice-versa, constitui um dos motivos implicados nas altas prevalências de bovinos infectados na região (Moré et al., 2011). Dessa forma, pode ser atribuído o mesmo padrão de transmissão do parasito para a espécie equina nessa região, acarretando maior soroprevalência de $S$. cruzi do que de $S$. neurona nos animais avaliados. Nesse sentido, deve-se levar em consideração que os cães possuem um convívio mais íntimo com os equinos nos haras pesquisados, o que sugere que o contato com cães seja superior ao contato de equinos com animais selvagens, como gambás, hospedeiros definitivos de S. neurona. Assim, supostamente, os equinos teriam maior exposição a esporocistos de $S$. cruzi na água ou no alimento do que de esporocistos de $S$. neurona.

Portanto, é de grande importância considerar, além do resultado positivo da sorologia, a presença de sinais clínicos, o histórico dos animais, a epidemiologia do protozoário (presença de gambás, hospedeiros definitivos) para dar início ao tratamento dos animais acometidos. Isso porque o tratamento é eficaz, porém é demorado e dispendioso para ser usado em todos os animais que apresentarem sorologia positiva, uma vez que a sorologia, por si só, não é capaz de diferenciar com precisão qual o agente etiológico ou se ele desencadeará a manifestação clínica da MEP.

Palavras-chave: sorologia, soroprevalência, mieloencefalite equina por protozoário, apicomplexa

\begin{abstract}
Sarcocystis neurona is the primary agent for Equine Protozoal Myeloencephalitis (EPM), important neurological disease characterized by behavior or muscular changes, that impairs animal performance and husbandry. Sarcocystis cruzi is a pathogen related to myositis in cattle. Although related the life cycles of the parasites are distinct. S. neurona has opossums (Didelphis spp.) and S. cruzi, dogs as definitive hosts. However, S. neurona and S. cruzi may undergo cross-reactivity in serological tests, interfering on results of EPM ante-mortem diagnostic tests. In the present study, serology of 189 mares was performed by indirect immunofluorescence antibody test, using antigens of $\mathrm{S}$. neurona and $\mathrm{S}$. cruzi in order to assess the exposure degree of animals to antigens. Analyzing the results, it was observed that most of the animals $(84.13 \%)$ reacted with at least one protozoal species and the number of animals which showed antibodies against $\mathrm{S}$. cruzi was greater than $\mathrm{S}$. neurona (80.42\% and $33.86 \%$, respectively) and a third of seropositive animals reacted to antigens of both species.
\end{abstract}

Keywords: serology, seroprevalence, equine protozoal myeloencephalitis, Apicomplexa 


\section{REFERÊNCIAS}

ANTONELLO, A.M.; PIVOTO, F.L.; CAMILLO, G. et al. The importance of vertical transmission of Neospora sp. in naturally infected horses. Vet. Parasitol., v.187, p.367-70, 2012.

DUBEY, J.P.; LINDSAY, D.S.; KERBER, C.E. et al. First isolation of Sarcocystis neurona from the South American opossum, Didelphis albiventris, from Brazil. Vet. Parasitol., v.95, p.295-304, 2001a.

DUBEY, J.P.; LINDSAY, D.S.; SAVILLE, W.J. et al. A review of Sarcocystis neurona and equine protozoal myeloencephalitis (EPM). Vet. Parasitol., v.95, p.89-131, 2001 b.

HAMIR, A.N.; MOSER, G.; GALLIGAN, D.T. et al. Immunohistochemical study to demonstrate Sarcocystis neurona in equine protozoal myeloencephalitis. J. Vet. Diagn. Invest., v.5, p.418-22, 1993.

HOANE, J.S.; GENNARI, S.M.; DUBEY, J.P. et al. Prevalence of Sarcocystis neurona and Neospora spp. infection in horses from Brazil based on presence of serum antibodies to parasite surface antigen. Vet. Parasitol., v.136, p.155-9, 2006.
JOHNSON, A.L.; BURTON, A.J.; SWEENEY, R.W. Utility of 2 immunological tests for antemortem diagnosis of equine protozoal myeloencephalitis (Sarcocystis neurona infection) in naturally occurring cases. J. Vet. Intern. Med., v.24, p.1184-9, 2010.

MACKAY, R.J.; GRANSTROM, D.E.; SAVILLE, W.J. et al. Equine protozoal myeloencephalitis. Vet. Clin. North Am. Equine Pract., v.16, p.405-25, 2000.

MORÉ, G.; ABRAHAMOVICH, P.; JURADO, S. et al. Prevalence of Sarcocystis spp. in Argentinean cattle. Vet. Parasitol., v.177, p.162165, 2011.

MORÉ, G.; BASSO, W.; BACIGALUPE, D. et al. Diagnosis of Sarcocystis cruzi, Neospora caninum, and Toxoplasma gondii infections in cattle. Parasitol. Res., v.102, p.671-675, 2008.

SAVILLE, W.J.; DUBEY, J.P.; OGLESBEE, M.J. et al. Experimental infection of ponies with Sarcocystis fayeri and differentiation from Sarcocystis neurona infections in horses. $J$. Parasitol., v.90, p.1487-91, 2004.

TENTER, A.M. Current research on Sarcocystis species of domestic animals. Int. J. Parasitol., v.25, p.1311-1330, 1995.

XIANG, Z.; HE, Y.; ZHAO, H. et al. Sarcocystis cruzi: comparative studies confirm natural infections of buffaloes. Exp. Parasitol., v.127, p.460-466, 2011. 